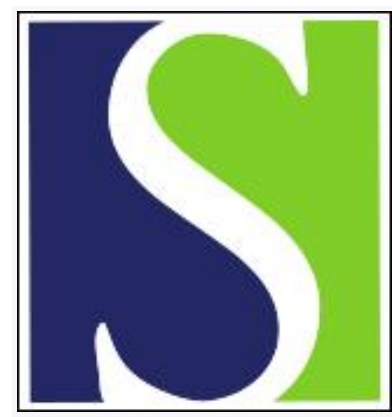

Scand J Work Environ Health 2012;38(6):568-576

https://doi.org/10.5271/sjweh.3300

Published online: 23 Apr 2012, Issue date: 01 Nov 2012

Long-term effects of biomechanical exposure on severe shoulder pain in the Gazel cohort

by Descatha A, Teysseyre D, Cyr D, Imbernon E, Chastang J-F, Plenet A, Bonenfant S, Zins M, Goldberg M, Roquelaure Y, Leclerc A

Affiliation: Université de Versailles Saint Quentin-Inserm, Centre for Research in Epidemiology \& Population Health, "Population-Based Epidemiological Cohorts" Research Platform, Villejuif, France. alexis.descatha@rpc.aphp.fr

Refers to the following texts of the Journal: 2005;31(6):409-437 2006;32(2):99-108 2006;32(4):294-299 2010;36(3):189-201 2011;37(1):37-44 2011;37(6):502-511

Key terms: biomechanical exposure; biomechanics; cohort study; France; Gazel cohort; long-term effect; occupational disease; occupational exposure; occupational exposure; shoulder pain

This article in PubMed: www.ncbi.nlm.nih.gov/pubmed/22527281 


\title{
Long-term effects of biomechanical exposure on severe shoulder pain in the Gazel cohort
}

\author{
by Alexis Descatha, MD, PhD, ${ }^{1,2}$ Denis Teysseyre, MD, ${ }^{1,3}$ Diane Cyr, PhD, ${ }^{1}$ Ellen Imbernon, MD, PhD, ${ }^{4}$ \\ Jean-François Chastang, PhD, ${ }^{3}$ Aurélia Plenet, MSc, ${ }^{1}$ Sébastien Bonenfant, MSc, ${ }^{1}$ Marie Zins, MD, PhD, ${ }^{1}$ \\ Marcel Goldberg, MD, PhD, ${ }^{1}$ Yves Roquelaure, MD, PhD, ${ }^{5}$ Annette Leclerc PhD ${ }^{1}$
}

\begin{abstract}
Descatha A, Teysseyre D, Cyr D, Imbernon E, Chastang J-F, Plenet A, Bonenfant S, Zins M, Goldberg M, Roquelaure Y, Leclerc A. Long-term effects of biomechanical exposure on severe shoulder pain in the Gazel cohort. Scand J Work Environ Health. 2012;38(6):568-576. doi:10.5271/sjweh.3300
\end{abstract}

\begin{abstract}
Objective We aimed to assess whether the risk factors for severe shoulder pain, especially exposure to arm elevation, were still relevant after a 12-year follow-up, even following retirement.

Methods All men participating in the ARPEGE ancillary study of the GAZEL cohort (followed-up since 1989) and who answered the 1994 or 1995 general GAZEL self-administered questionnaire were included. Weight and self-reported exposure (arm elevation $>90^{\circ}$ with and without carrying loads) over the entire working life were collected at baseline (1994-1995). Shoulder pain and its intensity were recorded in 1994-1995 and again in 2006. Shoulder pain was measured on an intensity or discomfort 6-point scale in 1994-1995 and on an 8-point scale in 2006. Severe shoulder pain was defined as point-rated higher than the mid-points ( $>3 / 6$ in 1994-1995 and >4/8 in 2006) while moderate pain was lower or equal to these thresholds.
\end{abstract}

Results At baseline, 1786 47-51-year-old men were included. In 1994-1995, moderate pain was observed among $8.5 \%(\mathrm{~N}=151)$ of men and severe shoulder pain among $14.6 \%(\mathrm{~N}=261)$. Exposure to arm elevation $>90^{\circ}$ while carrying loads was significantly associated with severe shoulder pain with $>25$ years of exposure [adjusted odds ratio $\left(\mathrm{OR}_{\mathrm{adj}}\right) 4.2,95 \%$ confidence interval $(95 \% \mathrm{CI}) 1.7-10.5$ ], taking into account age, sports, smoking habits, history of shoulder trauma, and body mass index. In 2006, when most of the subjects had retired, 1482 men $(83.0 \%)$ answered the questionnaire, $17.3 \%$ of them with severe shoulder pain; the association between exposure to arm elevation $>90^{\circ}$ while carrying loads and severe shoulder pain was still significant $\left(\mathrm{OR}_{\mathrm{adj}} 3.3\right.$, 95\% CI 1.3-8.0), and remained so when subjects with shoulder pain at baseline were excluded.

Conclusions Among men, the effect of high shoulder exposure (arm elevation $>90^{\circ}$ while carrying loads) during working life on severe shoulder pain remains even after retirement. Extended surveillance and prevention should be offered to these workers.

Key terms biomechanics; cohort study; France; occupational disease; occupational exposure.

Shoulder pain is a relatively common condition and a cause of disability in the general population. The 12 -month prevalence of shoulder pain in the general population ranges between $7-47 \%$ depending on the population studied and the definition used $(1,2)$. Silverstein et al (3) reported a claim incidence rate for shoulder disorders of 54.0 per 10000 workers per year in the US. In France, neck and shoulder disorders incidence was $7.3 \%$ and $12.5 \%$ among men and women, respectively, between 1990-1995 (4), and the 3-year incidence in a high repetitive work population setting was $29 \%$ among men and $21 \%$ among women (5). In the Cosali survey, the prevalence of the syndrome of the rotator cuff was $7 \%$ in $2002-2004$, with $65 \%$ of persistence of shoulder symptoms three years later $(6,7)$.

Some reviews have summarized the known occupa-

1 Université de Versailles Saint Quentin-Inserm, Centre for Research in Epidemiology \& Population Health, "Population-Based Epidemiological Cohorts" Research Platform, Villejuif, France.

2 AP-HP, Poincaré University Hospital, Occupational health department, Garches, France.

3 INSERM, Centre for Research in Epidemiology \& Population Health, Epidemiology of Occupational \& Social Determinants of Health, Villejuif, France.

4 Department of Occupational Health, National Institute for Public Health Surveillance (InVS), St-Maurice, France.

5 LUNAN University, Laboratory of Ergonomics and Epidemiology in Occupational Health, University of Angers, Angers, France.

Correspondence to: Dr Alexis Descatha, U1018, Unité de pathologie professionnelle, CHU Poincaré, 104 bd Poincaré, 92380 Garches, France. [E-mail: alexis.descatha@rpc.aphp.fr] 
tional risk factors of shoulder pain and disorders $(8-10)$ : the biomechanical factors associated with shoulder pain and rotator cuff syndrome are shoulder abduction and flexion, heavy lifting, forceful manual exertion, repetitive movements, use of vibrating hand tools and cumulative exposure to these factors. Although true inflammatory tendinopathies exist, most workers have prolonged shoulder symptoms that correspond histologically to the degeneration of the normally highly arranged collagen fiber structure (11). Considering these elements, it could be hypothesized that occupational determinants of shoulder disorders are involved not only when they are present, but also long afterwards. A prospective study in a general population found that physical workload increases the risk of subsequent clinical shoulder disorders and that the effects seem to be long-term (12), but the effect of retirement (ie, cessation of exposure) was not examined.

We studied a sub sample of men from the GAZEL cohort (the ARPEGE study) to investigate whether known occupational factors associated with severe shoulder pain at baseline were still relevant 12 years later, even after retirement.

\section{Methods}

\section{Cohort}

The GAZEL cohort was established in 1989. Its members are volunteers recruited among the employees of Electricité de France and Gaz de France (EDF-GDF), the French national utility for energy production and distribution. EDF-GDF employed approximately 150000 workers of diversified trades and socioeconomic status throughout France. At baseline in 1989, the cohort included 20625 volunteers, men aged 40-50 and women $35-50$ years. In January of each year (including 1994, 1995, and 2006), participants receive a general questionnaire about their lifestyle, health and occupational situation. In addition, more than 40 ancillary research projects explore specific themes, some using additional specific questionnaires (13).

\section{Sample}

The ARPEGE ancillary study was designed to analyze musculoskeletal disorders of the upper and lower limbs (14). In 1994-1995, a sample was selected among GAZEL participants, including all blue-collar and clerical workers, half of the managers, and one quarter of the supervisors. In the present study, we included only the ARPEGE study men who answered the 1994 or the 1995 general GAZEL self-administered questionnaire (see figure 1). Women were not included in these analyses because of the low prevalence of their exposure to biomechanical factors.

\section{Exposure and covariates}

In 1994-1995 (baseline), all included subjects filled out both the annual GAZEL and the specific ARPEGE selfadministered questionnaires. Therein were recorded: age, body mass index (BMI) [continuous variable divided into four categories: $\geq 18.5-<25 \mathrm{~kg} / \mathrm{m}^{2}$ (normal), $<18.5$ $\mathrm{kg} / \mathrm{m}^{2}$ (underweight), $\geq 25-<30 \mathrm{~kg} / \mathrm{m}^{2}$ (overweight), $\geq 30$ $\mathrm{kg} / \mathrm{m}^{2}$ (obese)], regular sports activity (yes/no), current smoker (yes/no), and previous major shoulder trauma (fracture, luxation: yes/no). Self-assessed lifetime occupational exposures for shoulders were also recorded. Based on preliminary analyses (15), the most relevant exposures were "arm elevation $>90^{\circ}$ while carrying loads" and "arm elevation $>90^{\circ}$ without carrying loads". Three categories were considered based on duration of exposure assessed at baseline: never exposed or exposed for $<1$ year, $1-25$ years, and $\geq 25$ years of exposure.

Information about socioprofessional group was recorded in 1989, and coded into 11 categories, such as blue-collar workers, technical supervisors, managers etc. Since age at retirement is rather early in France, especially at EDF-GDF, almost all subjects had retired by 2006 .

\section{Outcome variables}

The main outcome variable considered in this study was severe shoulder pain in the previous year. At baseline, it was defined in the ARPEGE self-administered questionnaire as pain or discomfort of $>3$ on a 6-point scale (one question). In the longitudinal analysis, severe shoulder pain was defined as pain or discomfort of $>4$ on an 8 point-scale in the 2006 GAZEL self-administered questionnaire. Moderate pain was defined as pain rating lower than these thresholds.

\section{Analysis}

Associations between occupational and personal factors, and moderate or severe shoulder pain at baseline (crosssectional analyses) were described using bivariate analyses (Chi square test). Multivariate analyses were performed using logistic regression: simple models were based on severe shoulder pain versus moderate and no pain grouped together, and a multinomial model was based on moderate versus no pain and severe versus no pain.

The association between factors present at baseline in 1994-1995 and moderate or severe shoulder pain 12 years later in 2006 (longitudinal analyses) was assessed using similar models, with two separate models: one 
among men without any shoulder pain at baseline (multinomial logistic model) and one among those who reported shoulder pain at baseline (either moderate and severe, simple logistic model. Another variable ("having retired before January $1^{\text {st }}, 2001^{\text {") }}$ ) was added to take into account early retirement. In the analysis among men with pain, severe intensity at baseline was also.

SAS, version 9.1, was used for all statistical analyses (SAS Institute Inc, Cary, NC, USA). Associations were considered statistically significant if the P-value was $<0.05$.

\section{Results}

\section{Cross-sectional analysis}

In 1994-1995, 1786 men answered the GAZEL and ARPEGE questionnaires (figure 1) and constituted the baseline sample. They were aged 47-51 years; $8.5 \%$ had moderate shoulder pain $(\mathrm{N}=151)$ and $14.6 \%(\mathrm{~N}=261)$ had severe shoulder pain; $54.7 \%(\mathrm{~N}=976)$ of subjects had a BMI $\geq 25 \mathrm{~kg} / \mathrm{m}^{2}$ [including 9.1\% $(\mathrm{N}=163)$ with a BMI $\geq 30 \mathrm{~kg} / \mathrm{m}^{2}$, table 1]. Arm elevation $>90^{\circ}$ while carrying

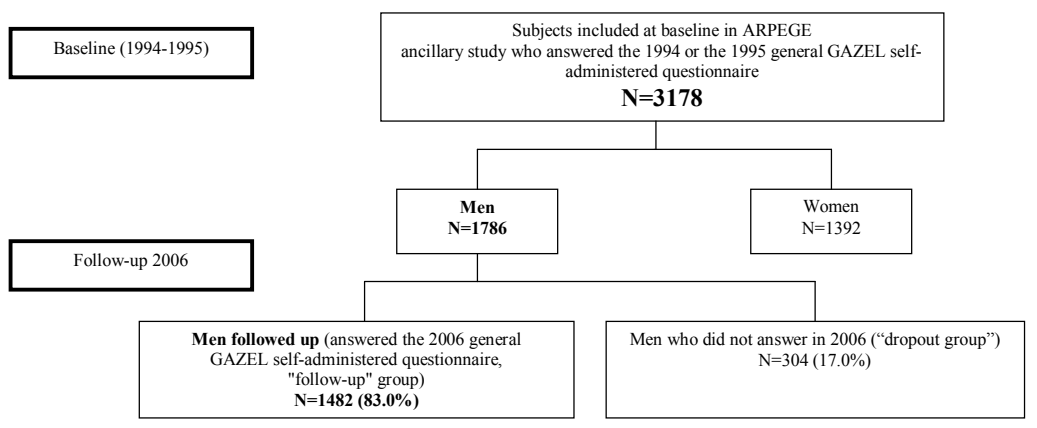

Figure 1. Flow diagram.

Table 1. Association between shoulder pain in 1994-1995 and personal and occupational factors assessed in 1994-1995 (bivariate analyses). [OR=0dds ratio; 95\% $\mathrm{Cl}=95 \%$ confidence interval; $\mathrm{BMI}=$ body mass index; $\mathrm{SD}=$ standard deviation]

\begin{tabular}{|c|c|c|c|c|c|c|c|c|c|c|c|c|c|}
\hline & \multirow{2}{*}{$\frac{\text { Total }}{\mathrm{N}}$} & \multicolumn{6}{|c|}{ Moderate shoulder pain } & \multicolumn{6}{|c|}{ Severe shoulder pain } \\
\hline & & Mean & SD & $\begin{array}{c}\text { Cases } \\
(\mathrm{N})\end{array}$ & $\%$ & $\begin{array}{c}\text { OR } \\
\text { (crude) }\end{array}$ & $95 \% \mathrm{Cl}$ & Mean & SD & $\begin{array}{l}\text { Cases } \\
(\mathrm{N})\end{array}$ & $\%$ & $\begin{array}{l}\mathrm{OR} \\
\text { (crude) }\end{array}$ & $95 \% \mathrm{Cl}$ \\
\hline Age (years) & $48.8^{a}$ & 48.8 & 1.33 & & & 0.99 & $0.88-1.12$ & 48.9 & 1.36 & & & 1.03 & $0.94-1.31$ \\
\hline BMI $\left(\mathrm{kg} / \mathrm{m}^{2}\right)$ & $26.1^{\mathrm{b}}$ & 26.8 & 3.20 & & & $1.07^{c}$ & $1.02-1.13$ & 26.3 & 3.20 & & & 1.02 & $0.98-1.08$ \\
\hline \multicolumn{14}{|c|}{ BMI (class, kg/m²) } \\
\hline$<18.5$ & 198 & & & 40 & 8.08 & 1.24 & $0.67-2.27$ & & & 26 & 13.13 & 0.90 & $0.56-1.45$ \\
\hline $18.5-25$ & 612 & & & 16 & 6.54 & 1.00 & & & & 89 & 14.54 & 1.00 & \\
\hline $25-30$ & 813 & & & 77 & 9.47 & $1.51^{\mathrm{c}}$ & $1.01-2.25$ & & & 120 & 14.76 & 1.06 & $0.78-1.43$ \\
\hline$\geq 30$ & 163 & & & 20 & 12.27 & $2.06^{c}$ & $1.16-3.66$ & & & 26 & 15.95 & 1.21 & $0.75-1.95$ \\
\hline \multicolumn{14}{|c|}{ Current smoker } \\
\hline No & 1386 & & & 131 & 9.45 & 1.00 & & & & 203 & 14.65 & 1.00 & \\
\hline Yes & 400 & & & 22 & 5.50 & $0.55^{c}$ & $0.35-0.88$ & & & 58 & 14.50 & 0.94 & $0.60-1.29$ \\
\hline \multicolumn{14}{|c|}{ History of shoulder trauma } \\
\hline No & 1575 & & & 118 & 7.49 & 1.00 & & & & 211 & 13.40 & 1.00 & \\
\hline Yes & 211 & & & 35 & 16.59 & $2.93^{c}$ & $1.93-4.46$ & & & 50 & 23.70 & $2.34^{c}$ & $1.64-3.35$ \\
\hline \multicolumn{14}{|c|}{ Regular sports } \\
\hline No & 1301 & & & 118 & 9.07 & 1.00 & & & & 194 & 14.91 & 1.00 & \\
\hline Yes & 485 & & & 35 & 7.22 & 0.77 & $0.52-1.14$ & & & 67 & 13.81 & 0.89 & $0.66-1.21$ \\
\hline \multicolumn{14}{|c|}{$\begin{array}{l}\text { Exposed to arm elevation }>90^{\circ} \\
\text { while carrying loads (years) }\end{array}$} \\
\hline$<1$ & 1396 & & & 117 & 8.38 & 1.00 & & & & 172 & 12.32 & 1.00 & \\
\hline $1-25$ & 301 & & & 25 & 8.31 & 1.13 & $0.72-1.79$ & & & 67 & 22.26 & $2.06^{c}$ & $1.50-2.84$ \\
\hline$\geq 25$ & 89 & & & 11 & 12.36 & 1.86 & $0.95-3.65$ & & & 22 & 24.72 & $2.53^{c}$ & $1.51-4.25$ \\
\hline \multicolumn{14}{|c|}{$\begin{array}{l}\text { Exposed to arm elevation }>90^{\circ} \\
\text { without carrying loads (years) }\end{array}$} \\
\hline$<1$ & 1252 & & & 102 & 8.15 & 1.00 & & & & 157 & 12.54 & 1.00 & \\
\hline $1-25$ & 395 & & & 35 & 8.86 & 1.22 & $0.81-1.83$ & & & 80 & 20.25 & $1.81^{c}$ & $1.34-2.44$ \\
\hline$\geq 25$ & 139 & & & 16 & 11.51 & 1.57 & $0.89-2.77$ & & & 24 & 17.27 & 1.53 & $0.95-2.47$ \\
\hline Total & 1786 & & & & 153 & & & & & 261 & & & \\
\hline
\end{tabular}

a $\mathrm{SD}=1.38$.

b $\mathrm{SD}=3.10$.

c $\mathrm{P}<0.05$. 
loads was found mostly among blue-collar workers and technical supervisors [ $\mathrm{N}=285 / 871$ (32.7\%) versus 98/880 $(11.1 \%)$ for the other categories, $\mathrm{P}<0.0001]$.

Regular practice of a sport or being a current smoker, were not statistically associated with shoulder pain in 1994-1995 (table 1). BMI was associated with moderate shoulder pain but not with severe shoulder pain. The same association was found for history of previous shoulder trauma. Arm elevation $>90^{\circ}$ while carrying loads (in working life) was significantly associated with shoulder pain, especially severe shoulder pain. After adjusting for age, BMI, regular sports, and history of shoulder trauma, exposure to arm elevation $>90^{\circ}$ while carrying loads remained significantly associated with severe shoulder pain at baseline (simple logistic model, table 2). A dose-response relationship was found between severe shoulder pain and duration of exposure in both the simple logistic and the multinomial models (table 2). Arm elevation $>90^{\circ}$ without carrying loads was not significantly associated with shoulder pain in any of the models.

\section{Follow-up}

Among respondents in 1994-1995, 304 men (17.0\%) did not answer the 2006 questionnaire (drop-out group). The other men were followed until 2006 (follow-up group). In 1994-1995, more subjects in the follow-up group declared having been exposed to arm elevation $>90^{\circ}$ without carrying loads in their working life than in the drop-out group. The proportion of subjects exposed to arm elevation $>90^{\circ}$ without carrying loads was $31.1 \%$ $(\mathrm{N}=461)$ in the follow-up group, versus $24.0 \%(\mathrm{~N}=73)$ in the drop-out group $(\mathrm{P}<0.05)$. Being overweight (BMI $\geq 25 \mathrm{~kg} / \mathrm{m}^{2}$, obesity included) was also more frequent in the follow-up group $(58.4 \%, \mathrm{~N}=865$ versus $36.5 \%$ $\mathrm{N}=111$ respectively, $\mathrm{P}<0.0001)$. However, the prevalence of severe shoulder pain at baseline was not significantly different between the two groups $(13.2 \%$, $\mathrm{N}=196$ in the follow up group versus $10.5 \%, \mathrm{~N}=32$ in the drop-out group, $\mathrm{P}>0.05$ ). Mean age was not statistically different between the two groups [48.8 years, standard deviation (SD) 1.3 in both groups, $\mathrm{P}>0.05]$. The proportion of subjects exposed to arm elevation $>90^{\circ}$ while carrying loads was $22.7 \%(\mathrm{~N}=336)$ in the follow-up group, versus $17.8 \%(\mathrm{~N}=54)$ in the drop-out group $(\mathrm{P}=0.06)$.

\section{Evolution between 1994-1995 and 2006}

Among the 1482 men in the follow-up group, the prevalence of severe shoulder pain in 2006 was higher than at baseline $(17.3 \%, \mathrm{~N}=257$ versus $14.9 \%, \mathrm{~N}=221$, figure 2); the mean age was 60.8 (range 59-63) years old, and $98 \%$ had retired $(55.7 \%$ of men retired before 1 January 2001, $N=826$ ). The prevalence of shoulder pain (severe and moderate) was also higher in 2006 than at baseline $(35.3 \%, \mathrm{~N}=523$ versus $23.5 \%, \mathrm{~N}=348)$.

Among the 231 men in the follow-up group who had severe shoulder pain in 1994-1995, $82(37.1 \%)$ also had severe shoulder pain in 2006, whereas among the 1134

Table 2. Association between moderate and severe shoulder pain in 1994-1995 and personal and occupational factors assessed in 1994-1995 (multivariate analyses). [0R $\mathrm{Rdj}_{\mathrm{ad}}=$ adjusted odds ratio; 95\% Cl=95\% confidence interval; $\mathrm{BMI}=$ body mass index]

\begin{tabular}{|c|c|c|c|c|c|c|}
\hline & \multirow{2}{*}{\multicolumn{2}{|c|}{$\begin{array}{c}\text { Simple logistic model } \\
\begin{array}{c}\text { Severe shoulder pain versus no } \\
\text { or moderate shoulder pain }\end{array}\end{array}$}} & \multicolumn{4}{|c|}{ Multinomial logistic model } \\
\hline & & & \multicolumn{2}{|c|}{$\begin{array}{l}\text { Moderate shoulder pain } \\
\text { versus no shoulder pain }\end{array}$} & \multicolumn{2}{|c|}{$\begin{array}{l}\text { Severe shoulder pain } \\
\text { versus no shoulder pain }\end{array}$} \\
\hline & $O R_{a d j}$ & $95 \% \mathrm{Cl}$ & $O \mathrm{R}_{\mathrm{adj}}$ & $95 \% \mathrm{Cl}$ & $O R_{a d j}$ & $95 \% \mathrm{Cl}$ \\
\hline Age (years) & 1.04 & $0.94-1.15$ & 1.00 & $0.88-1.14$ & 1.04 & $0.94-1.16$ \\
\hline BMI $\left(\mathrm{kg} / \mathrm{m}^{2}\right)$ & 1.00 & $0.96-1.05$ & $1.06^{\mathrm{a}}$ & $1.01-1.12$ & 1.01 & $0.96-1.06$ \\
\hline \multicolumn{7}{|c|}{ Current smoker } \\
\hline No & 1.00 & & 1.00 & & 1.00 & \\
\hline Yes & 0.94 & $0.67-1.33$ & $0.55^{a}$ & $0.33-0.90$ & 0.89 & $0.62-1.26$ \\
\hline \multicolumn{7}{|c|}{ History of shoulder trauma } \\
\hline No & 1.00 & & 1.00 & & 1.00 & \\
\hline Yes & $1.92^{a}$ & $1.31-2.81$ & 3.09 a & $1.96-4.88$ & $2.27^{a}$ & $1.53-3.36$ \\
\hline \multicolumn{7}{|c|}{ Regular sports } \\
\hline No & 1.00 & & 1.00 & & 1.00 & \\
\hline Yes & 0.87 & $0.63-1.21$ & 0.62 & $0.40-0.96$ & 0.83 & $0.60-1.15$ \\
\hline \multicolumn{7}{|c|}{ Exposed to arm elevation $>90^{\circ}$ while carrying loads } \\
\hline$<1$ year & 1.00 & & 1.00 & & 1.00 & \\
\hline $1-25$ & $1.57^{\mathrm{a}}$ & $1.03-2.39$ & 0.95 & $0.53-1.71$ & $1.56^{\mathrm{a}}$ & $1.02-2.39$ \\
\hline$\geq 25$ & $3.21^{\text {a }}$ & $1.46-7.07$ & 1.52 & $0.56-4.12$ & $3.38^{a}$ & $1.51-7.55$ \\
\hline \multicolumn{7}{|c|}{ Exposed to arm elevation $>90^{\circ}$ without carrying loads } \\
\hline$<1$ year & 1.00 & & 1.00 & & 1.00 & \\
\hline $1-25$ & 1.42 & $0.96-2.10$ & 1.27 & $0.75-2.13$ & 1.45 & $0.98-2.17$ \\
\hline$\geq 25$ & 0.73 & $0.35-1.52$ & 1.27 & $0.55-2.93$ & 0.75 & $0.36-1.58$ \\
\hline
\end{tabular}




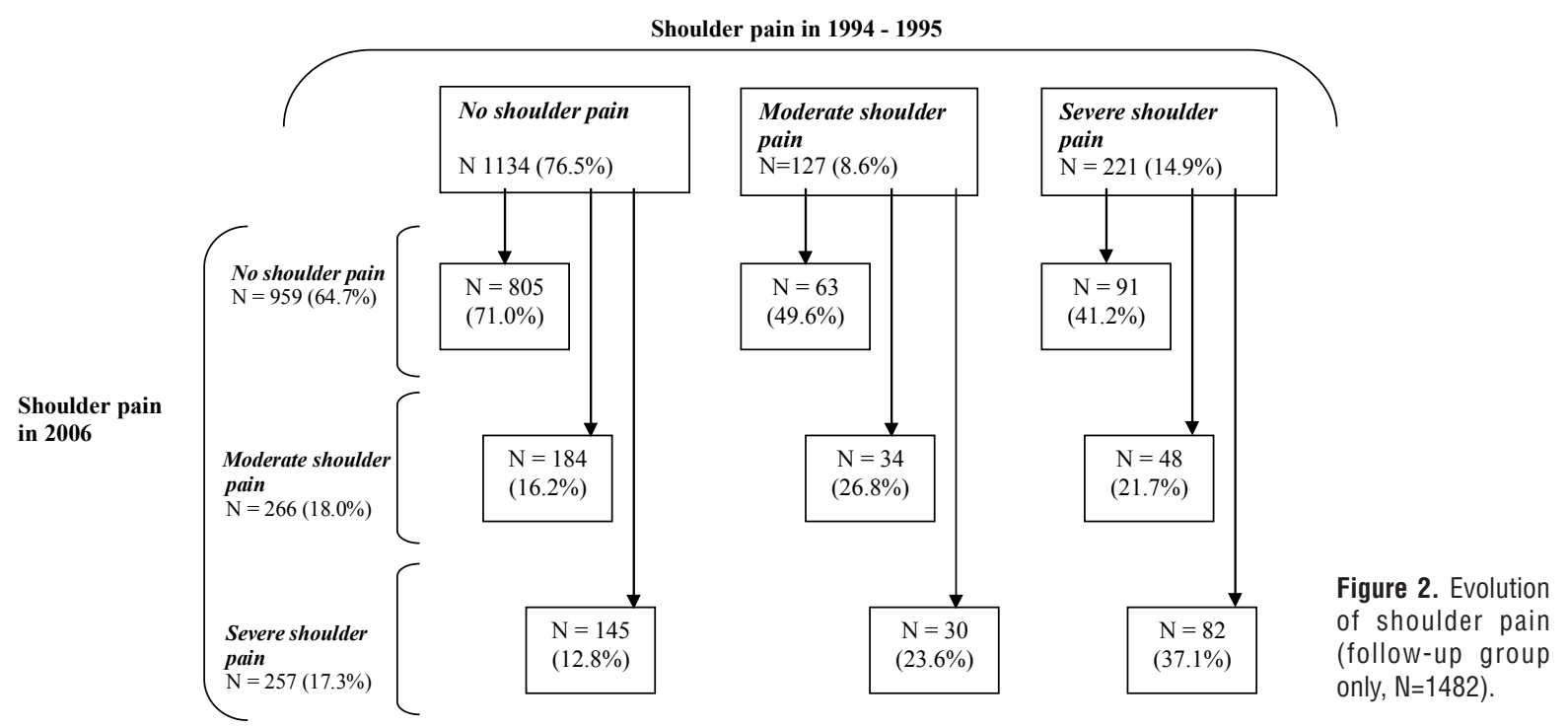

who did not report pain at baseline, $12.8 \%(\mathrm{~N}=145)$ had severe shoulder pain in 2006 (figure 2).

The difference in prevalence of severe shoulder pain between men who retired before 1 January 2001 and those who retired later was not statistically significant (18.6\% versus $16.9 \%, \mathrm{P}>0.05)$.

\section{Association between the baseline variables and severe} shoulder pain in 2006

Exposure to arm elevation $>90^{\circ}$ while carrying loads reported in 1994-1995 was still significantly associated with severe shoulder pain in 2006 after adjustment for the same confounding factors as in the previous analyses, and additional adjustment for date of retirement [adjusted odds ratio $\left(\mathrm{OR}_{\mathrm{adj}}\right) 3.53,95 \%$ confidence interval (95\% CI) 1.01-12.42], but no dose-response relationship was observed anymore.

In analyses restricted to men who did not report any shoulder pain in 1994-1995 $(\mathrm{N}=1134)$, the $\mathrm{OR}_{\text {adj }}$ for exposure to arm elevation $>90^{\circ}$ while carrying loads reported in 1994-1995 was similar (table 3). The influence of work exposure on the persistence (or recurrence) of shoulder pain among workers with shoulder pain at baseline is shown in table 4 .

\section{Discussion}

Assessed at baseline, shoulder biomechanical exposure in working life, more precisely exposure to arm elevation $>90^{\circ}$ while carrying loads, was associated with severe shoulder pain in this study among men, taking into account personal confounders (age, BMI, history of shoulder trauma). This association was weaker 12 years later but remained statistically significant. Analyses restricted to men without pain at baseline showed similar results.

Selection effects must be discussed. No statistical difference in severe (or moderate) shoulder pain at baseline was observed between the follow-up and the drop-out groups, even though the lifetime prevalence of exposure to biomechanical factors was only slightly higher in the follow-up group (low magnitude of difference) (14). Selection effects at inclusion and attrition during the follow-up have been studied previously in the GAZEL cohort: the initial participation of men in the whole GAZEL cohort was mostly influenced by lifestyle characteristics such as alcohol consumption, being overweight and health or cultural factors, while dropping out was mostly explained by the occurrence of major health problems $(16,17)$. Here, the difference in the prevalence of being overweight in the two groups might lead to a potential underestimation of shoulder pain in our final sample. The prevalence of shoulder pain was however similar to the $23.4 \%$ prevalence of shoulder symptoms found in a 1-year prospective study among 436 active workers conducted at 12 different worksites (18). It was also similar to the prevalence of shoulder pain in the previous year $(22.5 \%)$ found in a historical cohort of 1886 men from three occupational groups (machinists, car mechanics and house painters) (19). Overall, even though the drop-out group was slightly different from the follow-up group (less overweight, more exposed to physical factors), the effect on the associations between the risk factors and the outcomes is expected to be minimal. Other potential selection effects could result 
Table 3. Association between moderate and severe shoulder pain in 2006, and personal and occupational factors assessed in $1994-$ 1995 among workers with no self-reported shoulder pain at baseline $\left[\mathrm{OR}_{\mathrm{adj}}=\right.$ adjusted odds ratio; $95 \% \mathrm{Cl}=95 \%$ confidence interval; $\mathrm{BMI}=$ body mass index; $\mathrm{SD}=$ standard deviation.]

\begin{tabular}{|c|c|c|c|c|c|c|c|c|c|c|c|c|c|}
\hline & \multicolumn{9}{|c|}{ Description } & \multicolumn{4}{|c|}{ Multinominal logistic model } \\
\hline & \multirow{2}{*}{$\frac{\text { Total }}{\mathrm{N}}$} & \multicolumn{4}{|c|}{ Moderate shoulder pain } & \multicolumn{4}{|c|}{ Severe shoulder pain } & \multicolumn{2}{|c|}{$\begin{array}{l}\text { Moderate versus no } \\
\text { shoulder pain }\end{array}$} & \multicolumn{2}{|c|}{$\begin{array}{l}\text { Severe versus no } \\
\text { shoulder pain }\end{array}$} \\
\hline & & Mean & SD & $\begin{array}{r}\text { Cases } \\
(\mathrm{N})\end{array}$ & $\%$ & Mean & SD & $\begin{array}{r}\text { Cases } \\
(\mathrm{N})\end{array}$ & $\%$ & $\mathrm{OR}_{\mathrm{adj}}$ & $95 \% \mathrm{Cl}$ & $O \mathrm{R}_{\mathrm{adj}}$ & $95 \% \mathrm{Cl}$ \\
\hline Age (years) & $48.8^{a}$ & 48.8 & 1.41 & & & 48.9 & 1.30 & & & 0.96 & $0.83-1.11$ & 0.90 & $0.76-1.06$ \\
\hline $\mathrm{BMI}\left(\mathrm{kg} / \mathrm{m}^{2}\right)$ & $26.0^{b}$ & 26.1 & 3.27 & & & 26.6 & 2.87 & & & 1.02 & $0.97-1.09$ & $1.08^{c}$ & $1.02-1.15$ \\
\hline \multicolumn{14}{|c|}{ Current smoker } \\
\hline No & 898 & & & 136 & 15.14 & & & 109 & 12.14 & 1.00 & & 1.00 & \\
\hline Yes & 236 & & & 48 & 20.34 & & & 36 & 15.25 & $1.53^{c}$ & $1.03-2.28$ & 1.37 & $0.87-2.15$ \\
\hline \multicolumn{14}{|c|}{ History of shoulder trauma } \\
\hline No & 1028 & & & 168 & 16.34 & & & 131 & 12.74 & 1.00 & & 1.00 & \\
\hline Yes & 106 & & & 16 & 15.09 & & & 14 & 13.21 & 0.82 & $0.45-1.52$ & 0.92 & $0.48-1.77$ \\
\hline \multicolumn{14}{|c|}{ Regular sports } \\
\hline No & 796 & & & 132 & 16.58 & & & 105 & 13.19 & 1.00 & & 1.00 & \\
\hline Yes & 338 & & & 52 & 15.38 & & & 40 & 11.83 & 0.93 & $0.63-1.35$ & 1.06 & $0.70-1.62$ \\
\hline \multicolumn{14}{|c|}{$\begin{array}{l}\text { Exposed to arm elevation }>90^{\circ} \\
\text { while carrying loads (years) }\end{array}$} \\
\hline$<1$ & 902 & & & 147 & 16.30 & & & 106 & 11.75 & 1.00 & & 1.00 & \\
\hline $1-25$ & 186 & & & 32 & 17.20 & & & 27 & 14.52 & 1.01 & $0.58-1.73$ & 0.93 & $0.51-1.70$ \\
\hline$\geq 25$ & 46 & & & 5 & 10.87 & & & 12 & 26.09 & 0.83 & $0.21-3.22$ & $4.03^{c}$ & $1.21-13.47$ \\
\hline \multicolumn{14}{|c|}{$\begin{array}{l}\text { Exposed to arm elevation }>90^{\circ} \\
\text { without carrying loads (years) }\end{array}$} \\
\hline$<1$ & 806 & & & 131 & 16.25 & & & 94 & 11.66 & 1.00 & & 1.00 & \\
\hline $1-25$ & 250 & & & 43 & 17.20 & & & 37 & 14.80 & 1.27 & $0.78-2.07$ & 1.50 & $0.87-2.56$ \\
\hline$\geq 25$ & 78 & & & 10 & 12.82 & & & 14 & 17.95 & 0.82 & $0.30-2.21$ & 0.59 & $0.19-1.83$ \\
\hline \multicolumn{14}{|c|}{$\begin{array}{l}\text { Retirement before } 1 \text { January } \\
2001\end{array}$} \\
\hline No & 664 & & & 113 & 17.02 & & & 76 & 11.45 & 1.00 & & 1.00 & \\
\hline Yes & 446 & & & 67 & 15.02 & & & 69 & 15.47 & 0.96 & $0.63-1.46$ & 1.40 & $0.87-2.23$ \\
\hline
\end{tabular}

from the specificity of the GAZEL cohort. The physical workload in this cohort corresponds mainly to electric distribution maintenance. This physical exposure is different from what can be observed in other activities (the construction industry for instance), probably explaining why exposure to arm elevation $>90^{\circ}$ without carrying loads was not found to be significant. Workers also kept their job for a long time, with an inter-quartile range of 10-25 years of exposure for most of self-assessed of biomechanical exposures. Hence the variability in exposure was limited. All these elements could explain why there was no clear dose-response relationship, especially in the longitudinal analysis. In addition, the strength of the association probably decreases with time since exposure. Finally, the early age at retirement in the cohort, from 55-65 years old at EDF-GDF, may also have played a role.

The fact that the exposure was self-reported must also be discussed: the authors of a recent review of shoulder disorders and occupational factors stated that in $29 \%$ of the selected studies, only questionnaires were used for the assessment of exposure (10). However, the description of the lifetime exposure to physical work- load in various socioprofessional groups suggested that self-reported exposure was probably accurate, especially "hands above shoulders" and manual handling (20). The validity of lifetime occupational exposure (versus current) is also debatable (21). However, taking into account the stability of the exposure in the cohort, recall bias is probably limited. Regarding the validity of self-reported weight and height, a small but statistically significant underestimation of the BMI $\left(0.29 \mathrm{~kg} / \mathrm{m}^{2}\right.$ on average) has previously been found in the whole GAZEL cohort (22).

Self-reported outcome is the most appropriate measure when studying pain or discomfort. We chose "severe" pain or discomfort as the main outcome, defined by a threshold at the middle of the scale as recommended from guidelines on chronic pain (23). High intensity of pain and presence of disability are closely correlated, especially for patients with symptoms rating over the $50 \%$ threshold $(14,23)$. Shoulder pain can result from different conditions, including rotator cuff syndrome, but we had no information on specific diagnoses. A previous study has found that risk factors of specific shoulder disorders differ from those of subjective complaints 
Table 4. Association between moderate and severe shoulder pain in 2006, and personal and occupational factors assessed in 1994-1995 among workers with self-reported shoulder pain at baseline $\left[\mathrm{OR}_{\mathrm{adj}}=\right.$ adjusted odds ratio; $95 \% \mathrm{Cl}=95 \%$ confidence interval; $\mathrm{BMI}=$ body mass index; $\mathrm{SD}=$ standard deviation]

\begin{tabular}{|c|c|c|c|c|c|c|c|c|c|c|c|}
\hline & \multicolumn{9}{|c|}{ Description } & \multirow{2}{*}{\multicolumn{2}{|c|}{$\begin{array}{c}\text { Simple logistic model } \\
\begin{array}{c}\text { Severe shoulder pain versus no or } \\
\text { moderate shoulder pain }\end{array}\end{array}$}} \\
\hline & \multirow{2}{*}{ Total } & \multicolumn{4}{|c|}{$\begin{array}{l}\text { Moderate shoulder } \\
\text { pain }\end{array}$} & \multicolumn{4}{|c|}{$\begin{array}{l}\text { Severe shoulder } \\
\text { pain }\end{array}$} & & \\
\hline & & Mean & SD & $\begin{array}{r}\text { Cases } \\
(\mathrm{N})\end{array}$ & $\%$ & Mean & SD & $\begin{array}{r}\text { Cases } \\
(\mathrm{N})\end{array}$ & $\%$ & $\mathrm{OR}_{\mathrm{adj}}$ & $95 \% \mathrm{Cl}$ \\
\hline Age (years) & 48.9 a & 48.8 & 1.26 & & & 48.9 & 1.30 & & & 1.17 & $0.93-1.46$ \\
\hline BMI $\left(\mathrm{kg} / \mathrm{m}^{2}\right)$ & $26.6^{b}$ & 26.3 & 3.03 & & & 26.6 & 3.18 & & & 1.03 & $0.95-1.11$ \\
\hline \multicolumn{12}{|c|}{ Current smoker } \\
\hline No & 287 & & & 69 & 24.04 & & & 90 & 31.36 & 1.00 & \\
\hline Yes & 61 & & & 13 & 21.31 & & & 22 & 36.07 & 0.99 & $0.52-1.91$ \\
\hline \multicolumn{12}{|c|}{ History of shoulder trauma } \\
\hline No & 277 & & & 69 & 24.91 & & & 83 & 29.96 & 1.00 & \\
\hline Yes & 71 & & & 13 & 18.31 & & & 29 & 40.85 & 1.74 & $0.96-3.18$ \\
\hline \multicolumn{12}{|c|}{ Regular sports } \\
\hline No & 268 & & & 64 & 23.88 & & & 82 & 30.60 & 1.00 & \\
\hline Yes & 80 & & & 18 & 22.50 & & & 30 & 37.50 & 1.24 & $0.69-2.23$ \\
\hline \multicolumn{12}{|c|}{$\begin{array}{l}\text { Exposed to arm elevation }>90^{\circ} \\
\text { while carrying loads (years) }\end{array}$} \\
\hline$<1$ & 244 & & & 59 & 24.18 & & & 72 & 29.51 & 1.00 & \\
\hline $1-25$ & 77 & & & 15 & 19.48 & & & 31 & 40.26 & $2.25^{c}$ & $1.07-4.70$ \\
\hline$\geq 25$ & 27 & & & 8 & 29.63 & & & 9 & 33.33 & 1.18 & $0.37-3.74$ \\
\hline \multicolumn{12}{|c|}{$\begin{array}{l}\text { Exposed to arm elevation }>90^{\circ} \\
\text { without carrying loads (years) }\end{array}$} \\
\hline$<1$ & 215 & & & 50 & 23.26 & & & 69 & 32.09 & 1.00 & \\
\hline $1-25$ & 100 & & & 25 & 25.00 & & & 32 & 32.00 & 0.67 & $0.33-1.38$ \\
\hline$\geq 25$ & 33 & & & 7 & 21.21 & & & 11 & 33.33 & 1.32 & $0.45-3.94$ \\
\hline \multicolumn{12}{|c|}{ Retirement before 1 January 2001} \\
\hline No & 204 & & & 52 & 25.49 & & & 71 & 34.80 & 1.00 & \\
\hline Yes & 140 & & & 29 & 20.71 & & & 40 & 28.57 & 0.51 & $0.28-0.96$ \\
\hline \multicolumn{12}{|c|}{ Severe shoulder pain in 1994} \\
\hline No & 127 & & & 34 & 26.77 & & & 30 & 23.62 & 1.00 & \\
\hline Yes & 221 & & & 48 & 21.72 & & & 82 & 37.10 & $2.52^{c}$ & $1.45-4.39$ \\
\hline
\end{tabular}

without clinical findings (24). However, a recent review has concluded that, for population-based etiological research and surveillance, simple definitions of shoulder disorders should normally suffice considering that complex definitions (eg, involving physical signs, more specific symptom patterns, and investigations) yield similar associations with occupational risk factors (25).

The results were adjusted for age, BMI, smoking, history of trauma, and regular sports considering the suspected role of these factors in shoulder pain or disorders $(26,27)$. Smoking was found to be associated with shoulder pain. Being overweight is suspected of being associated with shoulder tendinitis: obesity presumably affects the shoulder mainly through impaired metabolism (glucose, lipids, collagen) (27). Being overweight was also was found to be associated with shoulder pain in a study on chronic shoulder pain (12). BMI was found to be associated with rotator cuff syndrome in a study of 733 workers (28). In our study, BMI might also be a risk factor for shoulder pain independently from occupational exposure. Shoulder traumatism, one of the most frequent causes of shoulder pain (29), was also found to be a possible independent risk factor for shoulder pain in our study, but sport, a known risk factor for rotator cuff syndrome, was not significantly associated with severe shoulder pain or discomfort. However, information about sports practice was partial and this variable was mostly used for adjustment purposes. In the 12 years of follow-up, changes in non-occupational exposure might also have occurred. For instance, the subjects may have tried new sports and other leisure activities involving the shoulder, such as gardening. Nevertheless, the level of exposure in these leisure activities is expected to be lower than for occupational factors, as frequently observed in populations of workers (28). It is also probable that in this period of time, no worker had been newly exposed to occupational biomechanical constraints.

After preliminary analyses, we selected "working with arm elevation $>90^{\circ}$ " (with and without handling loads) to study the long-term effect of biomechanical exposure on the shoulder. It is also one of the known 
occupational factors associated with shoulder pain (8-10) especially in association with other constraints $(10,12,28)$. Miranda et al (12) carried out a comprehensive national survey among a representative sample $(\mathrm{N}=7217)$ of the Finnish adult population in 1977-1980. Twenty years later, the subjects were invited to be reexamined. After excluding those with diagnosed shoulder disorders at baseline, 883 subjects were available for the analyses. Exposure to several physical factors increased the risk further, with an adjusted OR of nearly 3 for $\geq 2$ exposures. Lifting heavy loads and working in awkward postures were significantly associated with shoulder disorders for women but not for men. The results remained similar after excluding those with any shoulder pain at baseline. The authors concluded that physical workload increases the risk of a subsequent clinical shoulder disorder and that the effects seem to be long-term. A previous population-based study has also reported that physical load factors may have long-lasting effects on shoulder tendinitis in the dominant side (30).

Handling loads alone was too closely correlated with arm elevation $>90^{\circ}$ while carrying loads to be studied separately in this cohort. Other occupational biomechanical risk factors (climbing stairs/ladders) could have been chosen for this study. However, considering the specificity of the population, the strong association between exposures, the results of preliminary analyses and the aim of the study, we decided to focus on arm elevation $>90^{\circ}$ with and without carrying loads. Repetitiveness and exposure to vibration were not available. Psychosocial factors were not studied given that there is insufficient evidence to conclude a relationship between shoulder disorders and these factors $(10,31)$

The main purpose of this study was to analyze the long-term determinants of severe shoulder pain among men, especially the role of arm elevation $>90^{\circ}$ while carrying loads. Our results tend to confirm that the factors associated with severe shoulder pain at baseline might be risk factors (or aggravating factors) in the long-term and even after retirement (ie, after cessation of exposure). Even though residual confounding is possible, the present results emphasize the need for surveillance of workers highly exposed to shoulder constraints. In terms of prevention, our findings suggest that losing weight and limiting occupational exposure could be appropriate, especially in view of the persistence of the effect 12 years later, even after retirement. Further studies are needed, conducted in populations including both genders, with more heterogeneity in the exposure to shoulder risk factors and a more precise assessment of past exposure. In future long-term studies, particular attention should be paid to medical diagnoses in order to differentiate pain related to degenerative disorders from pain due to other conditions.

\section{Acknowledgments}

The authors express their thanks to EDF-GDF, especially to the Service Général de Médecine de Contrôle and to the "Caisse centrale d'action sociale du personnel des industries électrique et gazière." We also wish to acknowledge the "Population-Based Epidemiological Cohorts" research platform responsible for the GAZEL database management. The GAZEL cohort study was funded by EDF-GDF and INSERM and received grants from the "Cohortes Santé TGIR Program." This study is part of the Workage project supported by the French National Research Agency (ANR) and the French Agency for Environmental and Occupational Health Safety (AFSSET).

\section{References}

1. Luime JJ, Koes BW, Hendriksen IJ, Burdorf A, Verhagen AP, Miedema HS et al. Prevalence and incidence of shoulder pain in the general population; a systematic review. Scand J Rheumatol. 2004;33(2):73-81. http://dx.doi. org/10.1080/03009740310004667.

2. Roquelaure Y, Ha C, Leclerc A, Touranchet A, Sauteron $\mathrm{M}$, Melchior $\mathrm{M}$ et al. Epidemiologic surveillance of upper-extremity musculoskeletal disorders in the working population. Arthritis Rheum. 2006;55(5):765-78. http:// dx.doi.org/10.1002/art.22222.

3. Silverstein B, Welp E, Nelson N, Kalat J. Claims incidence of work-related disorders of the upper extremities: Washington state, 1987 through 1995. Am J Public Health. 1998;88(12):1827-33. http://dx.doi.org/10.2105/AJPH.88.12.1827.

4. Cassou B, Derriennic F, Monfort C, Norton J, Touranchet A. Chronic neck and shoulder pain, age, and working conditions: longitudinal results from a large random sample in France. Occup Environ Med. 2002;59(8):537-44. http://dx.doi. org/10.1136/oem.59.8.537.

5. Leclerc A, Chastang JF, Niedhammer I, Landre MF, Roquelaure Y. Incidence of shoulder pain in repetitive work. Occup Environ Med. 2004;61(1):39-44.

6. Roquelaure Y, Bodin J, Ha C, Petit LM, Descatha A, Chastang JF et al. Personal, biomechanical, and psychosocial risk factors for rotator cuff syndrome in a working population. Scand J Work Environ Health. 2011;37(6):502-11. http://dx.doi. org/10.5271/sjweh.3179.

7. Serazin C, Bodin J, Chiron E, Ha C, Bidron P, Meritet F et al. COSALI: preliminary results of the follow-up of salaried workers suffering from rotator cuff syndrome. Bull Epid Hebd (BEH). 2010;5-6:43-4.

8. Bernard BP. Musculoskeletal disorders and workplace factors: a critical review of epidemiologic evidence for work-related musculoskeletal disorders of the neck, the upper-limb, and low back. National Institute of Occupational Safety and Health, 
editor. Cincinnati: 1997 p. 97-141.

9. van der Windt DA, Thomas E, Pope DP, de Winter AF, Macfarlane GJ, Bouter LM et al. Occupational risk factors for shoulder pain: a systematic review. Occup Environ Med. 2000;57(7):433-42. http://dx.doi.org/10.1136/oem.57.7.433.

10. van Rijn RM, Huisstede BM, Koes BW, Burdorf A. Associations between work-related factors and specific disorders of the shoulder-a systematic literature review. Scand J Work Environ Health. 2010; 36(3):189-201. http://dx.doi. org/10.5271/sjweh.2895.

11. Wilson JJ, Best TM. Common overuse tendon problems: A review and recommendations for treatment. Am Fam Physician. 2005;72(5):811-8.

12. Miranda H, Punnett L, Viikari-Juntura E, Heliovaara M, Knekt P. Physical work and chronic shoulder disorder. Results of a prospective population-based study. Ann Rheum Dis. 2008;67(2):218-23. http://dx.doi.org/10.1136/ ard.2007.069419.

13. Goldberg M, Leclerc A, Bonenfant S, Chastang JF, Schmaus A, Kaniewski N et al. Cohort profile: the GAZEL Cohort Study. Int J Epidemiol. 2007;36(1):32-9. http://dx.doi.org/10.1093/ ije/dyl247.

14. Descatha A, Cyr D, Imbernon E, Chastang JF, Plenet A, Bonenfant $\mathrm{S}$ et al. Long-term effects of biomechanical exposure on severe knee pain in the Gazel cohort. Scand J Work Environ Health. 2011; 37(1):37-44. http://dx.doi. org/10.5271/sjweh.3123.

15. Teysseyre D, Leclerc A, Cyr D, Chastang JF, Imbernon $\mathrm{E}$, Bonenfant $\mathrm{S}$ et al. Long-term effects of occupational biomechanical factors on intense shoulder pain in Gazel Cohort. Arch Mal Prof Environ. 2011;72(1):89.

16. Goldberg M, Chastang JF, Leclerc A, Zins M, Bonenfant S, Bugel I et al. Socioeconomic, demographic, occupational, and health factors associated with participation in a longterm epidemiologic survey: a prospective study of the French GAZEL cohort and its target population. Am J Epidemiol. 2001; 154(4):373-84. http://dx.doi.org/10.1093/ aje/154.4.373.

17. Goldberg M, Chastang JF, Zins M, Niedhammer I, Leclerc A. Health problems were the strongest predictors of attrition during follow-up of the GAZEL cohort. J Clin Epidemiol. 2006; 59(11):1213-21. http://dx.doi.org/10.1016/j. jclinepi.2006.02.020.

18. Silverstein BA, Viikari-Juntura E, Fan ZJ, Bonauto DK, Bao S, Smith C. Natural course of nontraumatic rotator cuff tendinitis and shoulder symptoms in a working population. Scand J Work Environ Health. 2006;32(2):99-108. http://dx.doi. org/10.5271/sjweh.985.

19. Svendsen SW, Bonde JP, Mathiassen SE, Stengaard-Pedersen K, Frich LH. Work related shoulder disorders: quantitative exposure-response relations with reference to arm posture. Occup Environ Med. 2004;61(10):844-53. http://dx.doi. org/10.1136/oem.2003.010637.

20. Stock SR, Fernandes R, Delisle A, Vezina N. Reproducibility and validity of workers' self-reports of physical work demands. Scand J Work Environ Health. 2005;31(6):409-37. http://dx.doi.org/10.5271/sjweh.947.

21. Miranda H, Gold JE, Gore R, Punnett L. Recall of prior musculoskeletal pain. Scand J Work Environ Health. 2006;32(4):294-9. http://dx.doi.org/10.5271/sjweh.1013.

22. Niedhammer I, Bugel I, Bonenfant S, Goldberg M, Leclerc A. Validity of self-reported weight and height in the French GAZEL cohort. Int J Obes Relat Metab Disord. 2000;24(9):1111-8. http://dx.doi.org/10.1038/sj.ijo.0801375.

23. French National Authority for Health (HAS). Chronic pain: recognition, evaluation and orientation [Douleur chronique : reconnaître le syndrome douloureux chronique, l'évaluer et orienter le patient]. Paris: HAS. 2008. 4-7-2009.

24. Miranda H, Viikari-Juntura E, Heistaro S, Heliovaara M, Riihimaki H. A population study on differences in the determinants of a specific shoulder disorder versus nonspecific shoulder pain without clinical findings. Am J Epidemiol. 2005;161(9):847-55. http://dx.doi.org/10.1093/aje/kwi112.

25. Palmer KT, Harris EC, Linaker C, Cooper C, Coggon D. Optimising case definitions of upper limb disorder for aetiological research and prevention: a review. Occup Environ Med. 2012;69(1):71-8. http://dx.doi.org/10.1136/ oemed-2011-100086.

26. Viikari-Juntura E, Shiri R, Solovieva S, Karppinen J, LeinoArjas P, Varonen $\mathrm{H}$ et al. Risk factors of atherosclerosis and shoulder pain--is there an association? A systematic review. Eur J Pain. 2008; 12(4):412-26. http://dx.doi.org/10.1016/j. ejpain.2007.08.006.

27. Gaida JE, Ashe MC, Bass SL, Cook JL. Is adiposity an under-recognized risk factor for tendinopathy? A systematic review. Arthritis Rheum. 2009;61(6):840-9. http://dx.doi. org/10.1002/art.24518.

28. Silverstein BA, Bao SS, Fan ZJ, Howard N, Smith C, Spielholz $P$ et al. Rotator cuff syndrome: personal, work-related psychosocial and physical load factors. J Occup Environ Med. 2008; 50(9):1062-76. http://dx.doi.org/10.1097/ JOM.0b013e31817e 7bdd.

29. van der Windt DA, Koes BW, de Jong BA, Bouter LM. Shoulder disorders in general practice: incidence, patient characteristics, and management. Ann Rheum Dis. 1995;54(12):959-64. http://dx.doi.org/10.1136/ard.54.12.959.

30. Shiri R, Varonen H, Heliovaara M, Viikari-Juntura E. Hand dominance in upper extremity musculoskeletal disorders. J Rheumatol. 2007;34(5):1076-82.

31. Macfarlane GJ, Pallewatte N, Paudyal P, Blyth FM, Coggon D, Crombez G et al. Evaluation of work-related psychosocial factors and regional musculoskeletal pain: results from a EULAR Task Force. Ann Rheum Dis. 2009;68(6):885-91. http://dx.doi.org/10.1136/ard.2008.090829.

Received for publication: 20 December 2011 